Marquette University

e-Publications@Marquette

School of Dentistry Faculty Research and

Publications

Dentistry, School of

$12-1-2007$

\title{
Volume Analysis of the Proximal Tibial Metaphysis
}

Kingsley Wang

Luis Eduardo Almeida

Marquette University, luis.almeida@marquette.edu

Alexis B. Olsson

Northwestern University

Accepted version. Journal of Oral and Maxillofacial Surgery, Vol. 65, No. 12 (December 2007):

2425-2429. DOI. (C) 2007 American Association of Oral and Maxillofacial Surgeons. Published by Elsevier Inc. Used with permission.

Luis Eduardo Almeida was affiliated with Department of Oral and Maxillofacial Surgery, Curitiba Evangelic Hospital, Curitiba, Paraná, Brazil at the time of publication. 


\section{Marquette University}

\section{e-Publications@Marquette}

\section{Dentistry Faculty Research and Publications/School of Dentistry}

This paper is NOT THE PUBLISHED VERSION; but the author's final, peer-reviewed manuscript. The published version may be accessed by following the link in the citation below.

Journal of Oral and Maxillofacial Surgery, Vol. 65, No. 12 (December 2007): 2425-2429. DOI. This article is (C) Elsevier and permission has been granted for this version to appear in e-Publications@Marquette. Elsevier does not grant permission for this article to be further copied/distributed or hosted elsewhere without the express permission from Elsevier.

\section{Volume Analysis of the Proximal Tibial Metaphysis}

Kingsley Wang DDS

Private Practice, Chicago, IL.

Luis Eduardo Almeida DDS

School of Dentistry, Marquette University, Milwaukee, WI

Professor, Department of Oral and Maxillofacial Surgery, Curitiba Evangelic Hospital, Curitiba, Paraná, Brazil.

Alexis B. Olsson DDS

Oral Surgeon, Department of Surgery, Northwestern University, Feinberg School of Medicine, Chicago, IL.

\section{Purpose}

The Vitrea 2 imaging software (Vital Images Inc, Minnetonka, MN) was used for the volume analysis of the proximal tibial metaphysis.

\section{Materials and Methods}

Eighteen computed tomography scans of the proximal tibia were processed through the software, and 3dimensional imaging of the proximal tibia was reconstructed. 


\section{Results}

The volume and area of the proximal tibia that were generated resulted in a mean area of $127 \mathrm{~cm}^{2}$ and a mean volume of $77.2 \mathrm{~cm}^{2}$.

\section{Conclusion}

This study supports the use of the proximal tibial metaphysis as a source of low to moderate volume of autologous bone. When compared with the accepted average volume of $25 \mathrm{~cm}^{2}$, the computed results showed that there could be up to 3 times the amount of bone available in the proximal tibial metaphysis. The reported volume of bone harvested from previous studies was based on need and not the total amount available; subsequently, the results showed the possibility of a larger resource of bone, which provides the surgeon with the volumetrical limits of the proximal tibia metaphysis.

The gold standard for procuring bone grafting material in maxillary and mandibular reconstructive procedures is autogenous bone. Whether harvested intraorally or extraorally, oral and maxillofacial surgeons have multiple autogenous sites to choose from. The surgical site may depend on the type (cortical and/or cancellous) and amount of bone required for the procedure. Intraoral donor sites include the mandibular ramus and symphysis, while extraoral sites include calvarial, costochondral, anterior and posterior iliac crest, and proximal tibial head. Common features to all extraoral harvest sites are the larger amounts of bone available for harvesting, addition of an extra surgical site, increased operative time, weakened donor sites, and possible increase in postoperative morbidity. $\underline{1}, \underline{2}, \underline{3}, \underline{4}, \underline{5}, \underline{6}, \underline{7}, \underline{8}, \underline{9}, \underline{10}$ However, the advantage of larger amounts of cortical and cancellous bone often outweighs the disadvantages of extraoral harvesting.

Choosing the proximal tibia as a donor site has been accepted with caution because of reasons such as: operator unfamiliarity, fear of damaging the epiphyseal cartilage in growing children, and possible poor quality and quantity of bone. On the other hand, the advantages of the proximal tibia as a donor site include a smaller incision, decreased blood loss, and minimized stripping of muscle and periosteum. Furthermore, with the possibility of immediate ambulation and loading on the tibia, an overnight hospital stay may be eliminated and thus decrease the overall cost to the patient. This leaves us with the question of bone quantity available for harvesting from the proximal tibia. Past studies have shown an average of $25 \mathrm{~cm}^{2}$ unpacked cancellous bone harvested from either the medial or lateral approach to the proximal tibial metaphysic. 10

Once the surgeon decides on the amount of autogenous bone needed to reconstruct a mandibular or maxillary defect, the cancellous bone donor site can then be appropriately chosen. For most in-office reconstructive procedures, the proximal tibia often adequately supplies the amount of bone needed; however, this alternative is often overlooked. The aim of this study is to use 3-dimensional (3D) imaging software for volume and area quantification of the proximal tibial metaphysis to provide the surgeon with a solid understanding of the tibial head and the available quantity of bone for harvesting.

\section{Materials and Methods}

Computed tomography scans (CT) of the tibia were randomly selected from the Northwestern Memorial Hospital (Chicago, IL) radiology imaging data base for the purpose of measuring volume and area of the proximal

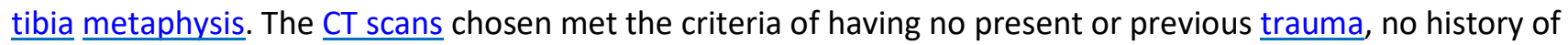
bone harvesting, and no artificial joints or implants in the proximal tibial metaphysis.

The Vitrea 2 (Vital Images Inc, Minnetonka, MN) is a 3D imaging and analysis software used in this study. It is a Windows XP based software running on the Intel Pentium 4 and Xeon processors. Vitrea was originally developed for advanced 3D visualization and analysis of structures from CT and magnetic resonance images. Further capabilities include creation of high quality cardiac images by using existing helical CT scanners, matching cardiac CT images with the corresponding echocardiogram signals, using automated vessel 
measurements to assist in presurgical diagnosis, and evaluation and stent planning in the abdominal aorta, carotid arteries, coronary arteries, and renal arteries. This software was created with ease of use in mind. An operator friendly graphic interface allows the clinician to manipulate around the 3D images and anatomic areas of interest.

When applying the Vitrea 2 for measuring the volume and area of the proximal tibia, 18 patients were randomly selected from the radiology imaging database at Northwestern Memorial Hospital. With the imaging of the proximal tibia (Fig 1), the software allowed each slice of the CT scan to be viewed. The CT slices ranged from 1.5 to $3 \mathrm{~mm}$. As each cut was visualized (Fig 2), the area desired was highlighted and marked for analysis (Fig 3 ). This process was performed for multiple cuts of the proximal tibia metaphysis until a simulated complete 3D image of the portion of the tibia to be measured was created. The cortical bone was omitted because only the cancellous bone is of interest for harvesting. The software provided the option for measuring both the volume and area of the 3D highlighted region. A 2D measurement of the maximum height and width of the proximal tibial metaphysis was also made at this point. The maximum height was set at $5 \mathrm{~cm}$ to simulate the depth of the curette used, and the width of the tibia was measured at the widest dimension in a medial lateral direction.

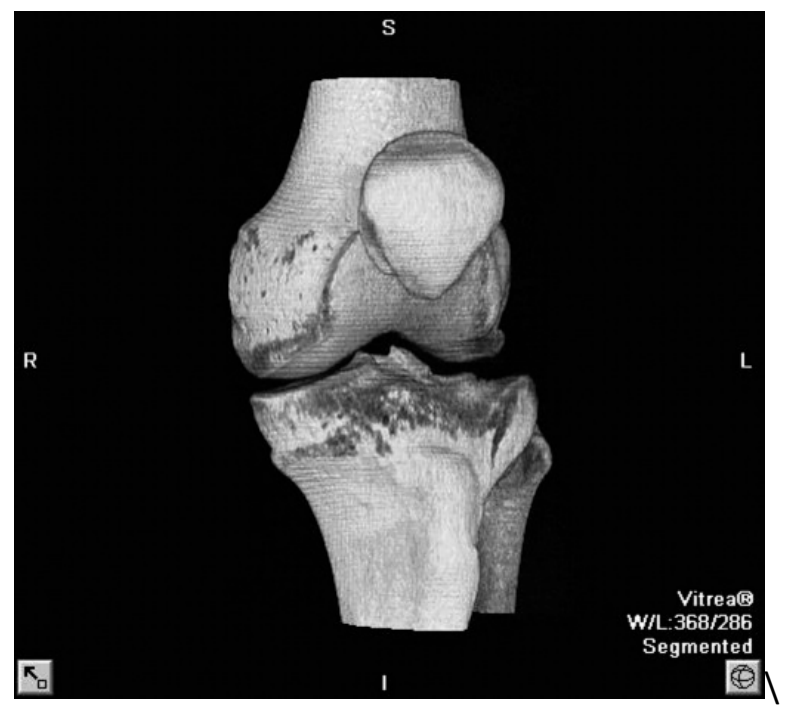

Figure 1. Three-dimensional image of the proximal tibia reconstructed with Vitrea imaging software.

Wang, Almeida, and Olsson. Volume Analysis of Proximal Tibial Metaphysis. J Oral Maxillofac Surg 2007.

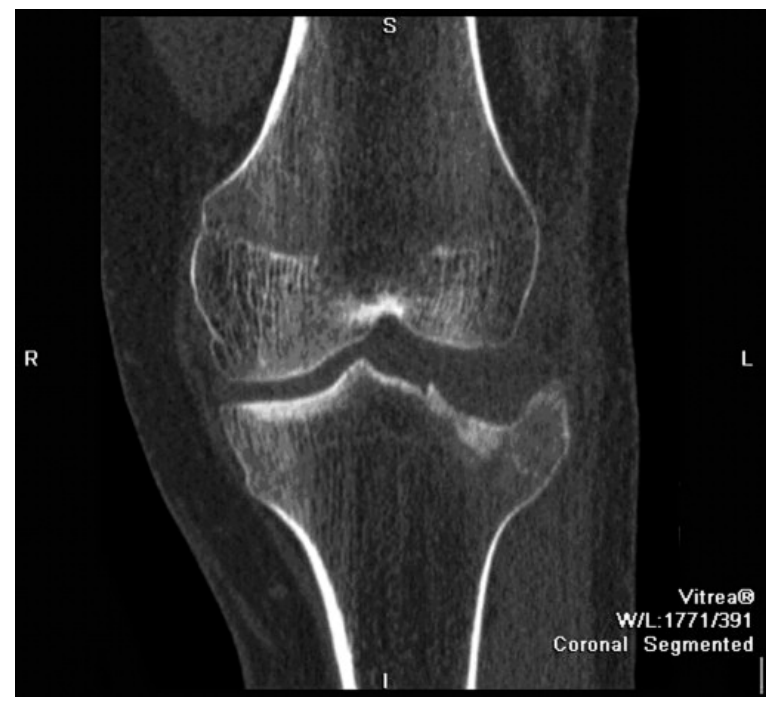


Figure 2. Two-dimensional image demonstrating the "slice" through the reconstructed proximal tibia image.

Wang, Almeida, and Olsson. Volume Analysis of Proximal Tibial Metaphysis. J Oral Maxillofac Surg 2007.

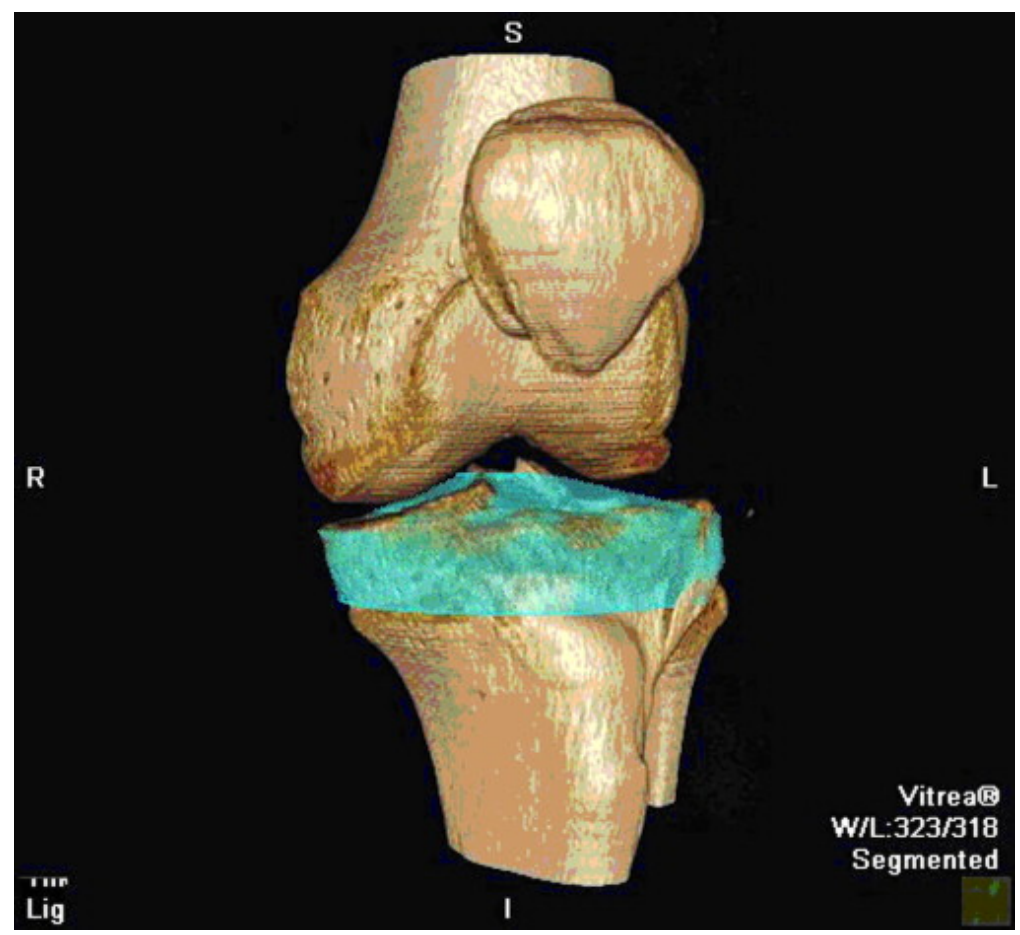

Figure 3. The highlighted region represents sections marked out for volume and area analysis.

Wang, Almeida, and Olsson. Volume Analysis of Proximal Tibial Metaphysis. J Oral Maxillofac Surg 2007.

\section{Results}

The CT scans of the 18 patients from the Northwestern Memorial Hospital radiology database were downloaded individually onto the computer containing the Vitrea 2 software. Once the large multi-image files were downloaded and opened through the Vitrea 2 software, the 3D images of the proximal tibia were then constructed and visualized. The 3D image of the proximal tibial metaphysis could be rotated and visualized in all 3 planes of space. The 3D image could be sectioned in an anterior-posterior, medial-lateral, or superior-inferior direction. Sectioning direction did not yield a difference in the tibial area or volume; however, for accuracy and consistency, all images were sectioned for analysis in an anterior-posterior direction.

Of the 18 patients chosen for analysis, 14 were males and 4 females. Mean volume of the proximal tibia was calculated to be $77.2 \mathrm{~cm}^{2}$, while the mean area was $127.7 \mathrm{~cm}^{2}$. Mean age of the patients was 44.8 years of age, with the mean age for the male patients at 43.9 years, and female patients at 47.8 years. Ages ranged from 20 to 67 years, with the males ranging from 20 to 67 years, and females ranging from 32 to 62 years (Table 1).

Table 1. Summary of the Mean Area and Volume

\begin{tabular}{|l|l|l|l|}
\hline & Total Patients $(\mathbf{N}=18)$ & Male $(\mathbf{N}=14)$ & Female $(\mathbf{N}=\mathbf{4})$ \\
\hline Mean area $\left(\mathrm{cm}^{2}\right)$ & 127.7 & 131.1 & 115.9 \\
\hline Mean volume $\left(\mathrm{cm}^{2}\right)$ & 77.2 & 79.3 & 69.9 \\
\hline
\end{tabular}

Wang, Almeida, and Olsson. Volume Analysis of Proximal Tibial Metaphysis. J Oral Maxillofac Surg 2007.

On further analysis of the data, male mean area and mean volume were found to be at $131.1 \mathrm{~cm}^{2}$ and $79.3 \mathrm{~cm}^{2}$, respectively, while female mean area and volume were at $115.9 \mathrm{~cm}^{2}$ and $69.9 \mathrm{~cm}^{2}$ (Table 2). 
Table 2. Summary of the Mean Age, Width, and Height

\begin{tabular}{|l|l|l|l|}
\hline & Total Patients $\mathbf{( N = 1 8 )}$ & Male $(\mathbf{N}=14)$ & Female (N =4) \\
\hline Mean age $(\mathrm{yr})$ & 44.8 & 43.9 & 47.8 \\
\hline Age range $(\mathrm{yr})$ & $20-67$ & $20-67$ & $32-62$ \\
\hline Mean width $(\mathrm{mm})$ & 69.7 & 71.6 & 62.9 \\
\hline Mean height $(\mathrm{mm})$ & 50.3 & 50.2 & 50.5 \\
\hline
\end{tabular}

Wang, Almeida, and Olsson. Volume Analysis of Proximal Tibial Metaphysis. J Oral Maxillofac Surg 2007.

Mean width of the proximal tibia measured from the medial pole to the lateral pole was $69.7 \mathrm{~mm}$. Mean width of the male versus female proximal tibia measured $71.6 \mathrm{~mm}$ versus $62.9 \mathrm{~mm}$, respectively (Table 1). The average tibial head height was $50.3 \mathrm{~mm}$. This was kept at a constant for simulation of curette depth.

Of the 18 tibias analyzed, 7 came from the right tibia and 11 came from the left. The right tibia mean area and volume were $131 \mathrm{~cm}^{2}$ and $82.9 \mathrm{~cm}^{2}$, while the left tibia mean area and volume were $125.1 \mathrm{~cm}^{2}$ and $73.6 \mathrm{~cm}^{2}$, respectively. The mean area for the male right $\underline{11}$ and left $\underline{2}$ proximal tibia were $135.6 \mathrm{~cm}^{2}$ and $127.7 \mathrm{~cm}^{2}$, respectively, while the female right 12 and left $13, \underline{14}$ proximal tibia were $109.1 \mathrm{~cm}^{2}$ and $118.1 \mathrm{~cm}^{2}$. Mean volumes of the male right and left proximal tibias were $84.5 \mathrm{~cm}^{2}$ and $75.4 \mathrm{~cm}^{2}$, respectively. While mean volumes of the female right and left proximal tibias were $73.0 \mathrm{~cm}^{2}$ and $68.8 \mathrm{~cm}^{2}$ (Table 3).

Table 3. Summary of the Mean Area and Volume Between Right and Left Proximal Tibia Metaphysis

\begin{tabular}{|l|l|l|}
\hline & Mean Area $\mathbf{( \mathbf { c m } ^ { 2 } )}$ & Mean Volume $\mathbf{( \mathbf { c m } ^ { 2 } )}$ \\
\hline Right (7) & 131.9 & 82.9 \\
\hline Left (11) & 125.1 & 73.6 \\
\hline Male right (6) & 135.6 & 84.5 \\
\hline Male left (8) & 127.7 & 75.4 \\
\hline Female right (1) & 109.4 & 73.0 \\
\hline Female left (3) & 118.1 & 68.8 \\
\hline
\end{tabular}

NOTE. Numbers in parentheses refer to total numbers of tibia scanned per category.

Wang, Almeida, and Olsson. Volume Analysis of Proximal Tibial Metaphysis. J Oral Maxillofac Surg 2007.

\section{Discussion}

As complex in-office procedures and the use of 1-day surgical centers increase in the practice of today's oral and maxillofacial surgeon, the use of allogenic and alloplastic materials are more popular than ever. Materials such as hydroxyapatite and mineralized or demineralized cadaveric bone give advantages of operator friendliness, eliminating a second surgery site, and decreasing overall surgical time; yet they do not substitute autogenous bone's properties for osteoconduction and osteoinduction. $\underline{14}, \underline{15}$

There are numerous sites for autogenous bone graft harvesting. The type and amount of bone needed dictates the likely donor site. The ilium is often the preferred donor site, which contains the highest cancellous bone volume and has the highest cancellous bone-to-cortical bone ratio.10 The maximum amount of uncompressed cancellous bone usually harvested from the anterior iliac crest is $50 \mathrm{~mL} .10$ Harvesting from the posterior iliac crest will yield 2 to 2.5 times the amount of bone when compared with the anterior iliac crest. Furthermore, posterior iliac crest bone harvesting yields less pain, blood loss, and complications when compared with the anterior approach.10 However, the disadvantages of harvesting from the posterior ilium include the addition of approximately 2 hours to the surgery, which mainly comes from downtime during patient repositioning, and the inability to simultaneously perform surgery on the head and the ilium. Major complication rates specifically related to iliac crest donor sites have been reported at $9.2 \%$, with minor complications rates reported at $20.7 \% .16$ 
Other autogenous bone harvest sites include the calvarium, rib, and proximal tibial metaphysis. The calvarium can produce a limited amount of corticocancellous strips. These strips have advantages of providing adaptable bone for orbital reconstruction and facial onlay grafts. Disadvantages include the limited amount of bone allowed for harvesting, scalp incision, and potential dural tears. The chief indication for costochondral graft harvesting is to provide an anatomically similar source of bone for mandibular joint reconstruction. The primary disadvantage is the potential chance of pneumothorax. Lastly, the use of the proximal tibial metaphysis as a harvest site may yield an average of $25 \mathrm{~mL}$ uncompressed cancellous bone. 1

By using the proximal tibia as a donor site, the advantages can provide the oral and maxillofacial surgeon with autogenous bone without the morbidity associated with other donor sites and, therefore, provide the patient with a superior result. Distinct advantages of tibial bone grafts include:

1) A relatively simple surgical procedure that can be performed under local anesthesia and does not require postoperative hospitalization. $\underline{6}, \underline{17}$

2) The duration of the operation for the harvest ranges from 20 to 30 minutes.

3) It is possible to harvest 10 to $25 \mathrm{~cm}^{2}$ of non-compressed cancellous bone. 1,13

4) The harvested graft consists of particulate autogenous cancellous bone of high biologic value.6, 11

5) The leg of the donor site is loadable immediately after surgery and patients rarely complain of pain and dysfunction. 1

6) The incidence of serious complications of tibial grafts is reported to range from $1.3 \%$ to $3.8 \%$, where as iliac graft is associated with complications of approximately $10 \% . \underline{1}$

The use of the Vitrea 2 software for the volumetric analysis of the proximal tibial metaphysis resulted in an overall mean of $77.2 \mathrm{~cm}^{2}$. Trends from these data also showed that male mean volumes are greater than the reported female mean volumes $\left(79.3 \mathrm{~cm}^{2}\right.$ vs $\left.69.9 \mathrm{~cm}^{2}\right)$, and the right tibia showed greater volumes when compared with the left (Table 3 ). Because the reported volume of bone harvested from past studies was taken based on need and not total available amount, we can determine from this computer analysis that the average proximal tibial metaphysis has more than enough available harvestable bone for most in-office reconstructive procedures. Furthermore, if there were a choice between the right or left tibia, the use of the right tibial head may be chosen because of the greater quantity of bone it may yield. The intent of this study is not to recommend an upper limit to the amount of bone available for harvesting, but it is intended to show volumetric anatomy to the surgeon and promote the proximal tibial metaphysis as a viable source of autogenous bone.

Future studies may include a larger population, use of stricter selection criteria (such as identifying patients with metabolic bone disease), and the use of bone densitometry techniques. The available bone density studies include single x-ray absorptiometry, peripheral dual x-ray absorptiometry, full-table dual x-ray absorptiometry, quantitative computed tomography, or quantitative ultrasonography, which can accurately provide the mass of all the components of the bone.

\section{References}

1 G.A. Catone, B.L. Reimer, D. McNeir, et al. Tibial autogenous cancellous bone as an alternative donor site in maxillofacial surgery: A preliminary report J Oral Maxillofac Surg, 50 (1992), p. 1258

2 R.H. Daffner Case report 592: Bone graft donor site of tibia Skel Radiol, 19 (1990), p. 73

$\underline{3}$ U. Heim, F. Damur-Thur Cancellous bone from the head of the tibia as autologous graft material Arch Orthop Unfallchir, 89 (1977), p. 211 [in German]

$\underline{4}$ K.G. Heiple, V.M. Goldberg, A.E. Powell, et al. Biology of cancellous bone grafts Orthop Clin North Am, 18 (1987), p. 179

$\underline{5}$ C.W. Hughes, P.J. Revington The proximal tibia donor site in cleft alveolar bone grafting: Experience of 75 consecutive cases J Craniomaxillofac Surg, 30 (2002), p. 12 
$\underline{6}$ N. Jakse, F.J. Seibert, M. Lorenzoni, et al. A modified technique of harvesting tibial cancellous bone and its use for sinus grafting Clin Oral Implants Res, 12 (2001), p. 488

7 P.H. Johnson Beware: Greenstick fracture of the proximal tibial metaphysis J Ark Med Soc, 80 (1983), p. 215

8 J.O. Krause, C.R. Perry Distal femur as a donor site of autogenous cancellous bone graft J Orthop Trauma, 9 (1995), p. 145

9 J.M. Lane, S.S. Harvinder Current approaches to experimental bone grafting Orthop Clin North Am, 18 (1987), p. 213

10 R.E. Marx Philosophy and particulars of autogenous bone grafting Oral Maxillofac Surg Clin North Am, 5 (1993), p. 599

$11 \mathrm{H}$. Burchardt Biology of bone transplantation Orthop Clin North Am, 18 (1987), p. 187

12 V. Alt, A. Nawab, D. Seligson Bone grafting from the proximal tibia J Trauma, 47 (1999), p. 555

$13 \mathrm{~W}$. Besly, P. Ward Booth Technique for harvesting tibial cancellous bone modified for use in children $\mathrm{Br} \mathrm{J}$ Oral Maxillofac Surg, 37 (1999), p. 129

14 R.W. Bucholz, A. Carlton, R.F. Holmes Hydroxyapatite and tricalcium phosphate bone graft substitutes Orthop Clin North Am, 18 (1987), p. 323

15 R.W. Bucholz, A. Carlton, R. Holmes Interpore, hydroxyapatite as a bone graft substitute in tibial plateau fractures Clin Orthop, 240 (1989), p. S3

16 E.D. Arrington, W.J. Smith, H.G. Chambers, et al. Complications of iliac crest bone graft harvesting Clin Orthop, 329 (1996), p. 300

17 R.M. O'Keefe, R.M. Riemer, S.L. Butterfield Harvesting of autogenous cancellous bone graft from the proximal tibial metaphysis J Orthop Trauma, 5 (1991), p. 469 